\title{
EFFECT OF EXCESS L-HISTIDINE DIET ON ACCUMULATION OF L-HISTIDINE IN ISOLATED RAT SMALL INTESTINE
}

\author{
Yukio NaKamura, ${ }^{1}$ Kyoden YASUmoto, and Hisateru MitsudA ${ }^{2}$ \\ Laboratory of Nutritional Chemistry, Department of Food Science and Technology, \\ Faculty of Agriculture, Kyoto University, Sakyo-ku, Kyoto 606
}

(Received Februaly 7, 1974)

\begin{abstract}
Effects of protein deprivation and excessive administration of L-histidine on the accumulation of L-histidine in rat small intestine in vitro were investigated using tissue strips and rings. Compared with a $20 \%$ casein diet, a non-protein diet and a $5 \%$ casein $+5 \%$ L-histidine diet significantly enhanced the accumulation of L-histidine per unit wet weight of the tissue strips. The amount of endogenous L-histidine in the intestine of the animals fed on the excess L-histidine diet was extremely larger than that of animals fed on $20 \%$ casein and non-protein diets. Net accumulation per unit wet weight of the strips, calculated by taking into account the endogenous levels of L-histidine, was still significantly higher for rats fed on non-protein and excess L-histidine diets. However, the accumulations expressed in terms of the whole animal were identical irrespective of the dietary regimens. Also, with the intestinal rings no such significant difference as with the intestinal strips was observed among rats with different dietary regimens. It is speculated that dietary conditions affect intestinal absorption by modifying intestinal thickness rather than by influencing the mucosal function to accumulate amino acid.
\end{abstract}

Numerous studies on the transport of amino acids and sugars in mammalian small intestine have been reported relating responses of the tissue to alterations in nutritional conditions. A set of observations has advanced evidence that a restricted but balanced diet not merely enhances the normally occurring active transport of amino acids and sugars including L-histidine (1-4), D-methionine $(5,6)$, D-glucose (1-3), D-galactose and 3-O-methyl-D-glucose $(5,6)$, but also enables the intestine to actively transport the substances such as D-histidine, D-fucose, D-

1 Present address: Laboratory of Biochemistry, Department of Agricultural Chemistry, Faculty of Agriculture, Gifu University, Naka, Kagamigahara 504.

2 中村征夫, 安本教傳, 満田久輝 
xylose $(5,6)$ and L-glucose $(7)$, which are not transported against their concentration gradient in the intestine of normally fed rats. Similarly, an augmentation of L-histidine transport capacity is demonstrated in the small intestine of rats fed either a $5 \%$ casein or a $20 \%$ gluten diet (8). These findings, taken together, imply that intestinal transport systems may respond, at least in part, to the quantity and quality of the diet so as to compensate for dietary conditions. On the other hand, an increase in dietary protein content from 0 to $75 \%$ with an incidental decrease in carbohydrate content from 75 to $0 \%$ was found to result in an increase in Lhistidine transport capacity in rat small intestine (9). Also, everted intestinal sacs of rats fed a $88 \%$ casein diet is reported to transport a significantly larger amount of L-leucine against its concentration gradient than did the intestinal sacs of rats fed a $13 \%$ casein diet (10). These constitute a second set of observations which is indicative of an adaptive mechanism for the intestinal transport system to the intake level of the nutrients.

The present authors demonstrated that a low protein $(5 \%$ casein) diet produces a significant increase in the transmural transport capacity of rat small intestine compared with a normal ( $20 \%$ casein) diet, and an excess L-histidine $(5 \%$ casein + $5 \%$ L-histidine) diet results in an even greater increase (11). The observed enhancement was not exclusively attributable to the reduced thickness or weight of the intestinal wall, nor accounted for any of the two mechanisms as mentioned above.

Previous in vitro works of the present and other investigators were mostly carried out using everted sacs prepared from the intestine of the animals of varied dietary treatments, and compared the transmural transport capacities on unit intestinal weight basis or in terms of the final serosal to mucosal concentration ratios. It is of particular interest to ascertain which of the processes involved in the transport mechanisms is most sensitive to the dietary regimens used in the previous paper (11). To explore this matter, the intestinal capacity to accumulate L-histidine was compared in normally fed, protein-deprived and excessively Lhistidine-administered animals on bases of unit intestinal weight and the whole animal.

\section{EXPERIMENTAL}

Animals and diets. Male growing albino rats of the Wistar strain were bred in an individual cage placed in a temperature and humidity controlled room, and were allowed to have free access to the experimental diets and water throughout the experimental periods. The animals were raised on a $20 \%$ casein diet until they weighed $200 \mathrm{~g}$ each. Some of the animals at this stage served for use in control experiments and referred to as 'group A. The remaining rats were divided into two groups and fed the following experimental diets for 10 days: group B, non-protein diet; group C, $5 \%$ casein $+5 \%$ L-histidine diet. The composition of the diets is shown in Table 1. 
Table 1. Composition of experimental diets (\%).

\begin{tabular}{lccc}
\hline \multirow{2}{*}{ Ingredients } & \multicolumn{3}{c}{ Diet fed to } \\
\cline { 2 - 4 } & Group A & Group B & Group C \\
\hline Casein & 20 & 0 & 5 \\
L-Histidine & 0 & 0 & 5 \\
Corn starch & 52 & 72 & 62 \\
Sucrose & 14 & 14 & 14 \\
Soybean oil & 7 & 7 & 7 \\
Cod liver oil & 1 & 1 & 1 \\
Mineral mixture & 4 & 4 & 4 \\
Vitamin mixture $^{\mathrm{b}}$ & 1 & 1 & 1 \\
Cellulose powder & 1 & 1 & 1 \\
\hline
\end{tabular}

a According to HARPER (12).

b Contain per $100 \mathrm{~g}$ in sucrose: (mg) thiamine, 30; riboflavin, 45; nicotinamide, 300; pyridoxine $\cdot \mathrm{HCl}, 30$; folic acid, 15 ; calcium pantothenate, 150 ; vitamin $\mathrm{B}_{12}$, 0.23 ; $\alpha$-tocopherol, 30 ; vitamin $\mathrm{K}_{3}, 5$; biotin, 1 ; (g) inositol, 1 ; choline chloride 15 ; ascorbic acid, 1.125.

Preparation of tissue. The animals that fasted on water available for $24 \mathrm{hr}$ were anesthetized with ether. The abdomen was opened by a midline incision, and all of the small intestine was rinsed out in situ with about $100 \mathrm{ml}$ of bicarbonatesaline buffered at $\mathrm{pH} 7.2(13)$. The entire intestine was separated from the mesenterium and placed in the buffered saline under continuous bubbling with a gas mixture of $95 \% \mathrm{O}_{2}+5 \% \mathrm{CO}_{2}$. Two different procedures were used to prepare the tissue specimens: first, the anterior and posterior quarters of the intestine were discarded, and the remaining middle segment was opened along the mesenterium to make a strip of the intestine; alternatively, the whole of the intestine was cut into rings of 1 to $2 \mathrm{~mm}$ length such as described by AGAR et al. (14).

Procedures for accumulation experiments. The tissue, prepared as described above, was incubated with $100 \mathrm{ml}$ of the buffered saline containing $5 \mathrm{mM} \mathrm{L}$ histidine at $37^{\circ} \mathrm{C}$ for the period indicated in the individual experiments. The flask containing the incubation mixture was shaken at 60 oscillation/min, and the mixture was gassed with $5 \% \mathrm{CO}_{2}$ in $\mathrm{O}_{2}$. At the end of the incubation period the tissue was removed from the medium as follows: the strip was removed, quickly rinsed in fresh saline and blotted on filter paper; the rings were filtered out, and washed with saline on filter paper. The fresh weight was obtained by weighing the removed tissue. The values in Tables 2 and 3 represent the fresh weight of middle half of the entire small intestine. The removed tissue was then homogenized with a 10 volumes of $5 \%$ trichloroacetic acid and the homogenate was cleared by centrifugation at $9,000 \times g$ for $10 \mathrm{~min}$. The resultant supernatant was extracted 4 times with each 3 volumes of ether and then adjusted to $\mathrm{pH} 2.2$ with $1.2 \mathrm{~N} \mathrm{HCl}$. After evacuation to remove remaining ether, an aliquot of the 
solution was analysed for L-histidine accumulated in free state in the tissue by employing an automatic amino acid analyser (Yanagimoto LC-5S).

\section{RESULTS}

Table 2 compares the body weight of the experimental animals, the wet weight of the middle half of the intestine per rat, and the amount of L-histidine accumulated in the intestinal strip when incubated with $5 \mathrm{~mm}$ L-histidine for $20 \mathrm{~min}$. All the values in Table 2 are given as the mean \pm SD of the results for 6 to 7 rats.

Table 2. A comparison of accumulated histidine in rat small intestine. ${ }^{a}$

\begin{tabular}{cccc}
\hline Group $^{\mathrm{b}}$ & $\begin{array}{c}\text { Body weightc } \\
(\mathrm{g})\end{array}$ & $\begin{array}{c}\text { Wet weight of } \\
\text { intestine }^{\mathrm{c}} \\
(\mathrm{g})\end{array}$ & $\begin{array}{c}\text { Amount of histidine } \\
\text { accumulated }^{\mathrm{d}} \\
(\mu \mathrm{moles} / \mathrm{g} \cdot 20 \mathrm{~min})\end{array}$ \\
\hline A (7) & $196 \pm 4$ & $2.41 \pm 0.42$ & $5.08 \pm 1.34$ \\
B (6) & $158 \pm 8$ & $1.63 \pm 0.32$ & $6.86 \pm 1.93$ \\
C (6) & $167 \pm 9$ & $1.67 \pm 0.10$ & $7.19 \pm 1.59$ \\
\hline
\end{tabular}

a Values are mean \pm SD.

b Numbers of rats are indicated in parentheses.

c Differences significant at $p<0.005$ between group A and groups B and C.

d. Differences significant at $p<0.05$ between group A and groups B and C.

The animals in groups B and C lost about $15-20 \%$ of their starting weight at the end of 10 days of special feeding, and their food intake amounted to about half of that when they had been on the $20 \%$ casein diet. Figure 1 represents a typical example of the growth curves for the animals in the experimental groups. These

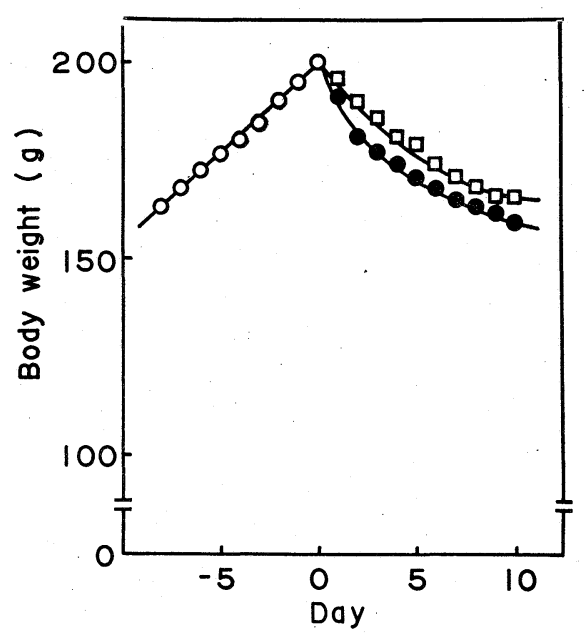

Fig. 1. Typical growth curves of experimental animals. Symbols denote the diets: $O$, normal diet (group A, $n=7$ );, , non-protein diet (group B, $n=6$ ); $\square$, excess L-histidine diet (group C, $n=6$ ). 
results parallel with those of the previous report (11). The wet weight of the intestine of the animals in groups B and $\mathrm{C}$ decreased to about $70 \%$ of the value found for group A, in association with losses of body weight during the period of feeding with such nutritionally inadequate diets. The difference between the values for group $\mathrm{A}$ and for either of groups $\mathrm{B}$ and $\mathrm{C}$ was statistically significant $(p<0.005)$, but insignificant between groups $\mathrm{B}$ and $\mathrm{C}$.

In six sets of experiments the mean DNA content $( \pm S D)$ of the small intestine, determined after extraction of DNA according the method of SCHNEIDER (15) and estimation of deoxypentose by the method of Dische (16) was $13.1 \pm 1.3,12.4 \pm$ 0.8 and $12.6 \pm 1.7 \mathrm{mg}$ per gram of the wet intestine in the rats of groups $\mathrm{A}, \mathrm{B}$ and $\mathrm{C}$, respectively. Based on the constancy of cellular DNA content, it was feasible to interpret these results as indicating that number of cells per wet weight remained roughly the same in the animals of these three groups, while total number of intestinal cells varied significantly by the experimental groups. Also, the experimental results expressed as a function of intestinal weight could be regarded as representing an average cellular capacity for accumulating amino acid.

The accumulation of L-histidine by the intestinal strips was determined after $20 \mathrm{~min}$ of the incubation. This incubation period was designed to overcome the difficulty of the tissue being impaired within $45 \mathrm{~min}$ and the epithelial layer occasionally coming off from the mucosal layer, although a linearity of L-histidine transport across the intestinal wall was well preserved in an incubation period of up to $40 \mathrm{~min}(11)$. There was no significant difference between the mean values for groups B and C, but these values were significantly higher than that for group A $(p<0.05)$. When considered from the standpoint of an absolute accumulation capacity, i.e. accumulation per strip, no significant difference was detectable among the groups: $11.9 \pm 2.4,11.0 \pm 2.8$ and $12.0 \pm 2.6 \mu$ moles for groups $\mathrm{A}, \mathrm{B}$ and $\mathrm{C}$, respectively. Much similar figures resulted when the accumulation data per unit weight given in Table 2 were multiplied by the intestinal wet weight data within the respective groups. Assuming that these accumulation capacities on absolute basis reflect the capacity of entire intestine, i.e. accumulation capacity of whole animal, it is likely that the difference observed when the data was expressed as a function of the strip weight is an apparent nature due to an actual thinning of the intestinal wall following the loss of body weight.

The influence of the endogenous L-histidine level was not taken into account in the descriptions noted above regarding the accumulation data shown in Table 2. The amount of endogenous L-histidine was measured after extraction from the tissue not incubated with amino acid. The results are shown in Table 3, indicating that the figures for group $\mathrm{C}$ were extremely larger than those for either of other groups. These results appear to be inconsistent with the hypothesis postulated by NeALE and WiSEMAN (7) regarding the augmented sugar transport capacity in the intestine from semi-starved rats; which contained lesser endogenous D-glucose than normal intestine. 
Table 3. A comparison of endogenous level of histidine in rat small intestine. ${ }^{a}$

\begin{tabular}{cccc}
\hline Group $^{\mathrm{b}}$ & $\begin{array}{c}\text { Body weight } \\
(\mathrm{g})\end{array}$ & $\begin{array}{c}\text { Wet weight of } \\
\text { intestine }^{\mathrm{d}} \\
(\mathrm{g})\end{array}$ & $\begin{array}{c}\text { Amount of endogenous } \\
\text { histidine }^{\mathrm{e}} \\
(\mu \mathrm{moles} / \mathrm{g})\end{array}$ \\
\hline A (5) & $193 \pm 8$ & $2.80 \pm 0.20$ & $0.087 \pm 0.009$ \\
$\mathrm{~B}(6)$ & $166 \pm 9$ & $1.82 \pm 0.41$ & $0.097 \pm 0.018$ \\
C (4) & $166 \pm 3$ & $2.12 \pm 0.41$ & $0.709 \pm 0.539$ \\
\hline
\end{tabular}

a Values are mean $\pm \mathrm{SD}$.

b Numbers of rats are indicated in parentheses.

c Differences significant at $p<0.005$ between group A and groups B and C.

d Differences significant at $p<0.005$ between group A and group B, and at $p<0.025$ between group $\mathrm{A}$ and group $\mathrm{C}$.

e Differences significant at $p<0.05$ between group $\mathrm{C}$ and groups $\mathrm{A}$ and $\mathrm{B}$.

Assuming that the actual absorptive capacity of the intestine is defined as the accumulated amount of L-histidine corrected by subtracting the endogenous level of the amino acid, i.e. the net accumulative capacity, then the absorptive capacity is estimated to be $6.76 \mu$ moles per $\mathrm{g}$ wet weight for $20 \mathrm{~min}$ and 6.48 for the animals in groups B and C, respectively, either of which is significantly higher than the value, 4.99, estimated for group A. These values, however, are not essentially different from those listed in Table 2. And again no statistical significance could be detected in the differences among the groups when the estimated values were compared in absolute term, not on a wet weight basis.

The data recorded in Table 2 were the amount of L-histidine found after $20 \mathrm{~min}$ of the incubation, and thus do not necessarily represent initial velocities nor maximal concentration attainable at steady state. In an attempt to answer the question whether the dietary regimens employed in this paper might affect the accumulation rate or the maximal concentration, an experiment was conducted in which the time course of the amino acid accumulation was followed by using such small rings of the intestine as described by AGAR et al. (14). The results are shown in Fig. 2, in which each point represents the mean of the values and each bar denotes SD. The amount of the amino acid accumulated for the first $7 \mathrm{~min}$ by the rings from protein-deprived rats, group B, was lesser than that found for other groups. However, statistical validity of this difference is highly questionable, since such differences can not be discernible nor reproducible at 14 and 21 min. Statistical tests failed to detect any significance in possible difference of the mean values between the animals of groups $\mathrm{A}$ and $\mathrm{B}$ at any time of the incubation except at $7 \mathrm{~min}$. The values for groups $\mathrm{C}$, however, were significantly higher at 30, 45 and $60 \mathrm{~min}$ than the corresponding values for groups $\mathrm{A}$ and $\mathrm{B}(p<0.05-0.10)$, i.e. excessive administration of L-histidine resulted in an increase in the maximal accumulation level of the intestinal rings but probably not in the accumulation rate. These vague, unexpected, results may be attributable to a limited number of experiments and, more likely, to a difference in the method of the tissue preparation. 

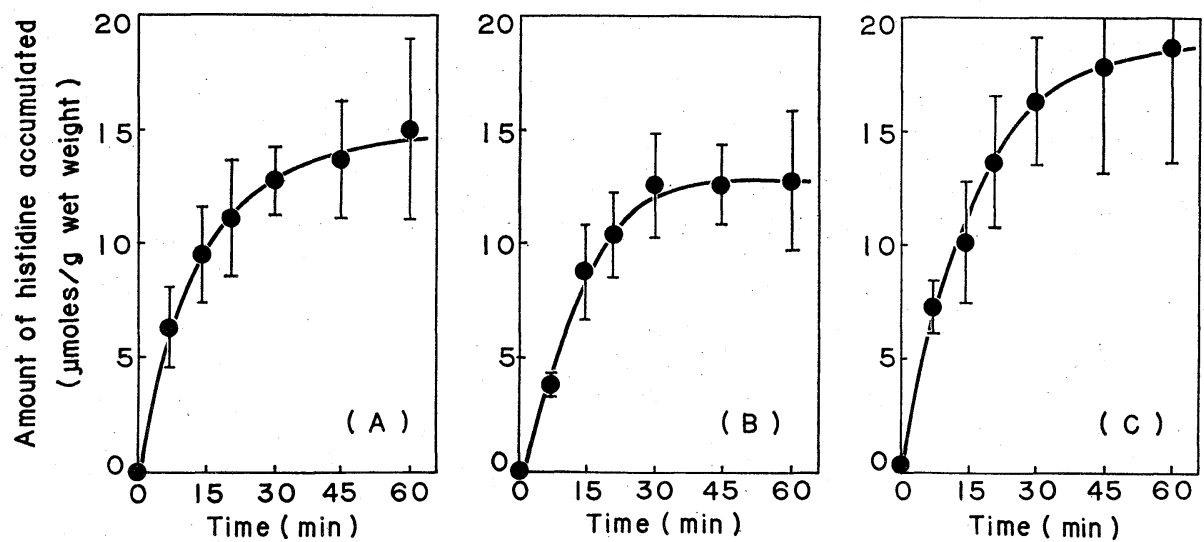

Fig. 2. Time-course of L-histidine accumulation in the intestinal rings from the animals in: (A), group A $(n=4)$; (B), group B $(n=4)$; (C), group C $(n=4)$. Bars denote SD. Statistical significance of the difference in the mean values is given in the text.

\section{DISCUSSION}

NeAle and Wiseman (7) have suggested that the enhanced intestinal transport of sugars by dietary restricted rats is, at least partially, responsible for the reduced endogenous content of D-glucose of the intestinal wall of such animals. Their suggestion is however in apparent contrast with the combined findings of the present and the previous paper (11) that L-histidine transport capacity is augmented by feeding animals with an excess L-histidine diet, while the endogenous L-histidine content of the intestine of such animals is significantly higher than that of control rats. It is not possible at present to interpret precisely finding that the intestine of the animals fed on the excess L-histidine diet is capable of retaining L-histidine at such a significant level as shown in Table 2 even after fasting by the animals for $24 \mathrm{hr}$ and the further extensive treatments of the removed intestine, including rinsing with saline, to obtain the tissue preparation. It may also be worthwhile to note here that no significant difference was found between the endogenous L-histidine contents of control intestine and of protein-deprived intestine.

Major aspects of the present investigation are closely associated with those of the previous investigation (11). Therefore, the findings in this paper should be compared with those of the previous paper with the view of providing detailed feasible explanations of the concerned phenomena.

The present investigation revealed that the amount of accumulated L-histidine and the net accumulation of the amino acid, latter value of which was estimated by subtracting the endogenous L-histidine content from the former value, are evidently higher in intestinal strips from the animals fed the non-protein diet (group B) and the excess L-histidine diet (group C) than in those from animals on the 
control diet (group A). These results parallel the previous finding that the ability of transmural transport of L-histidine was augmented by protein depletion and by excessive administration of L-histidine.

The present results on the effects of protein depletion and excessive administration of L-histidine depart from those previously reported in that under nutritional conditions, the differences between the accumulation (uncorrected) and net accumulation (corrected) capacities of the strips were insignificant, while the difference between transmural transport capacities of the everted sacs were significant. The values for L-histidine in Tables 2 and 3 are expressed in terms of unit wet weight of the intestine. Assuming that the accumulation capacity of the entire intestine, in other words the capacity per rat, is reflected by multiplication of these values by the total wet weight of the intestine, no significant difference could be detected among the animals in groups A, B and C. It is therefore quite likely that an actual decrease in the thickness of the intestine brought about by inadequate diets increases relatively the capacity of the unit weight intestine. It is very tempting to conclude that the change in the capacity per unit wet weight is of an apparent nature. These results and the conclusion, however, again differ from previously reported results.

The total DNA content of the intestine in the control group was significantly greater than in other two groups $(p<0.01)$, but when expressed as a function of intestinal weight, no significant difference was detectable. In view of the constancy of cellular DNA content, this finding supports the suggestion that the average cellular accumulation capacity is represented by the experimental results which were expressed as a function of intestinal weight. However, the DNA content, although reflecting cell number, in no way differentiates one cell type from another. There is considerable evidence in the literature that histological integrity of the epithelium is adequately preserved in the intestine of rats kept on inadequate diets, while atrophy of muscle layers and disappearance of adipose tissue are occurring $(17,18)$. Since the morphological integrity presumably reflects an intact function, such morphologically disproportionate changes as often emphasized in the literature (19) lend a support to the conclusion that dietary regimens employed in this paper have no significant influence on total accumulation capacity while affecting significantly the total weight or cell numbers of the gut.

The discrepancies between the effects of protein depletion and excessive administration of L-histidine on the transmural transport and on the accumulation capacity are obvious, implying that these dietary regimens may influence the function of some processes involved in the transport mechanism in such a way as to facilitate the transmural transport but not tissue accumulation.

The difference or discrepancies enumerated above are with relative impunity attributable to the difference in the technique employed: the use of strips to measure accumulation in the present paper and, in opposition, the use of the everted sacs 
to measure the transmural transport in the previous paper. Some of these discrepancies, however, can be explained by assuming the following appropriate model for intestinal absorption: (1) entrance of amino acid across the epithelial membrane from the mucosal fluid into the intestinal tissue; (2) retention within the tissue against the concentration gradient; and (3) transfer across the muscular layer into the serosal fluid. The data obtained by the use of the everted sacs inevitably reflect the overall properties of the mechanisms functioning in the transmural transfer and, therefore, have direct but complex bearing on the functions of all the first, second and third processes. On the other hand, the data by the tissue accumulation method, such as used in this paper, very likely reflect the capacity of the tissue to take up the amino acid within the tissue, and thus represent primarily the function of the second process of all others. It is thus likely that protein depletion and excessive administration of L-histidine do not affect accumulation capacity on an entire intestine basis but do affect it on a unit weight basis by producing a significant reduction in the tissue weight, especially in muscular layer which is known to compose a significant diffusion barrier in overall transport process but least in absorptive mucosal layer. The intestine thereby may acquire the ability to release the amino acid into the serosal fluid more easily than the intestine of normal thickness; that is, the nutritionally inadequate dietary regimens possibly result in an enhancement of the third process in the postulated model.

The experimental results shown in Fig. 2 are in apparent contradiction with those in Table 2. In comparing the mean values at 21 min of incubation in Fig. 2 with the values in Table 2, it can be seen that the intestinal rings accumulate amino acid more rapidly than the intestinal strips, and it may be concluded that entry of the amino acid into the rings is much easier than in the strips. This enhanced rate is probably a reflection of a greater surface area of the rings resulting from artificial exposition of absorptive surface by slicing, reducing dependence on the thickness of the intestine. The ring preparation, as having often been claimed, reflects little the events observed with the strips and the sacs unless the extent of the changes was so remarkable, as was the case with the animals in group C. With these interpretations and inferences, the experimental results in Fig. 2 do not appear to be incompatible with those in Table 2, but suggest that intestinal thickness is an important consideration in the studies of transmural transport, but is less important in tissue accumulation with the strips, and is even of lesser importance with the rings. Thus, these lend partial but indirect support to the hypothesis that the dietary regimens primarily influence the diffusion process involved in the intestinal transport mechanisms.

\section{REFERENCES}

1) Neame, K. D. and Wiseman, G., J. Physiol., 146, 10 P (1959).

. Kershaw, T. G., Neame, K. D., and Wiseman, G., J. Physiol., 152, 182 (1960). 
3) Hindmarsh, J. T., Kilby, D., Ross, B., and Wiseman, G., J. Physiol., 188, 207 (1967).

4) Wright, C. L. and Barber, H. E., Biochem. J., 115, 1075 (1969).

5) Neale, R. J. and Wiseman, G., J. Physiol., 204, 116 P (1969).

6) Neale, R. J. and Wiseman, G., J. Physiol., 205, 159 (1969).

7) Neale, R. J. and Wiseman, G., J. Physiol., 198, 601 (1968).

8) Shimomura, A., Osaka Univ. Med. J., 16, 415 (1964).

9) Goldsmith, R. M., Munday, K. A.; and Turner, M. R., Proc. Nutrition Soc., 30, 80 A (1971).

10) Scharrer, E., Experientia, 28, 267 (1972).

11) Nakamura, Y., Yasumoto, K., and Mitsuda, H., J. Nutrition, 102, 359 (1972).

12) HARPER, A. E., J. Nutrition, 68, 405 (1959).

13) Krebs, H. A. and Henseleit, K., Hoppe-Seyler's Z. Physiol. Chem., 211, 33 (1932).

14) Agar, W. T., Hird, F. J. R., and Sidhu, G. S., Biochim. Biophys. Acta, 14, 80 (1954).

15) Schneider, W. C., J. Biol. Chem., 164, 747 (1946).

16) Dische, Z., in E. Chargaff and J. N. Davidson (Editors), The Nucleic Acids, Academic Press, New York, Vol. I, p. 285 (1955).

17) Hopper, A. F., Wannemacher, R. W., Jr., and McGovern; P. A., Proc. Soc. Exptl. Biol. Med., 128, 695 (1968).

18) Hill, R. B., Jr., Prosper, J., Hirschfield, J. S., and Kern, F., Jr., Exptl. Mol. Pathol., 8, 66 (1968).

19) Herskovic, T., Am. J. Clin. Nutrition, 22, 300 (1969). 